This is a pre-publication version of the final manuscript. The final version can be found here: http://dx.doi.org/10.1080/0309877X.2012.706807

To cite this article: Anna Sutton, David Taylor \& Carol Johnston (2012): A model for exploring student understandings of plagiarism, Journal of Further and Higher Education, 


\title{
A Model for Exploring Student Understandings of Plagiarism
}

\author{
Anna Sutton $^{\mathrm{a}}$, David Taylor ${ }^{\mathrm{b}}$ and Carol Johnston ${ }^{\mathrm{c}}$ \\ ${ }^{a}$ Manchester Metropolitan University Business School, Manchester, UK \\ ${ }^{b}$ formerly at Leeds University Business School, Leeds, UK \\ ${ }^{c}$ Faculty of Business and Economics, University of Melbourne
}

* Corresponding Author: Dr Anna Sutton, Manchester Metropolitan University Business School, Aytoun Building, Aytoun Street, Manchester M1 3GH, UK tel: +441612473955

Email: a.sutton@mmu.ac.uk

Acknowledgements: We are very grateful for the assistance of Professor Keith Glaister, Dean of the Management School, University of Sheffield in collecting the data for this study. 


\title{
A Model for Exploring Student Understandings of Plagiarism
}

\begin{abstract}
A clear understanding of how students view plagiarism is needed if the extensive efforts devoted to helping them engage in high quality scholarship are to be worthwhile. There are a variety of views on this topic but theoretical models to integrate the literature, take account of international differences and guide practitioners are limited. Using a large, international student sample, this paper presents just such a model. Over 2,500 university students in the UK and Australia completed a questionnaire rating the perceived "seriousness" of various plagiarism-related actions in an individual assignment. Factor analysis identified three underlying themes: Dishonest acts, Poor Referencing, and Group Work. Group comparisons indicated statistically significant differences in student understanding dependent on previous region of study, current faculty and level of study, with the former two emerging as more influential than the latter. This three factor model provides practitioners with a methodology for integrating the many different studies in the area and gaining a broader overview of student understanding of plagiarism. In particular, it highlights how plagiarism related to group work is considered by students to be far less serious than other types. Given the increasing emphasis on group work in higher education, the implications of this for policy and practice are discussed. Importantly, the study also notes that effect sizes were small, suggesting findings in this study as in other studies may not represent substantive differences in student perceptions. A single, universal approach to educating students about plagiarism may be as effective as approaches tailored to the individual's background.
\end{abstract}

Keywords: plagiarism, student perception, academic misconduct, group work 


\section{Introduction}

Debates around the meaning and understanding of plagiarism are fraught, with some respected academics claiming publicly that plagiarism no longer "holds up - we live in a world of cut and paste" (Smith, 26 Feb 2006), while university regulations continue to equate plagiarism with cheating and maintain severe penalties for students who engage in it. Alongside this debate, it has been noted by Park (2003) that plagiarism is an increasing problem in universities, particularly in relation to electronically available information. He estimates that over $50 \%$ of students cheat at university. In some cases, the incidence of selfreported cheating is as high as $87 \%$ (Caruana et al., 2000).

Institutions often aim to provide a clear definition of plagiarism in an attempt to help students to avoid it. While a dictionary definition of plagiarism is simple to come by, in the academic world of constructed meanings, shared values and different cultures, the definition can be blurred. There is evidence that institutional-level definitions either do not filter down to staff and students or can be interpreted differently in specific scenarios (Barrett and Cox, 2005). Carroll (2007, p13) considers definitions of plagiarism appropriate for a Higher Education context and suggests that a typical definition is simply "submitting someone else's work as your own". The author also considers the question of defining collusion and concludes that it is extremely difficult to clearly delineate collusion (not acceptable) and collaboration (acceptable). In light of the increasing attention given to the problem of plagiarism and the efforts to establish benchmarking practices for Higher Education Institutions (Tennant and Duggan, 2008), an understanding of how students view plagiarism will enable teaching staff to support students' engagement in high quality scholarship.

\section{Understandings of plagiarism}

While evidence indicates that there is general agreement between university students and staff about what constitutes exam cheating (Livosky and Tauber, 1994), similar levels of 
agreement are not found in understandings of plagiarism. There is widespread confusion over what constitutes plagiarism and whether "intent" is necessary for plagiarism to occur, with many students being convinced that plagiarism can happen "by accident" and therefore very worried that they might unwittingly be subject to severe penalties (Ashworth et al., 1997). The effect that this concern can have on the students was clearly demonstrated in a study by Levy and Rakovski (2006), where they found that even "honest" students will avoid a lecturer who inflicts serious punishments on students who plagiarise. Subsequent work by the same authors (Rakovski and Levy, 2007, p468) notes:

"Exam-related cheating and plagiarism are considered the most serous dishonest acts. Out of class work including collaborating on homework and not contributing to a group project are considered less dishonest acts"

Consistent with this, Dick, Sheard and Markham (2001, cited in Brimble and StevensonClarke, 2005) found that students broadly held the same view of what was acceptable academic practice (for example, resubmitting an assignment from a previous subject in a different subject) and what was not acceptable (for example, exam cheating), but these views did not necessarily correspond with University policy.

Staff, like students, also disagree in their understandings of plagiarism. Staff from different faculties have varying definitions of plagiarism and its relation to academic cheating (Flint et al., 2006) and disagree on how serious the consequences for students should be (Barrett and Cox, 2005). Park (2003) describes how staff view plagiarism as anything from serious malpractice to nothing more than misunderstanding or poor etiquette.

In addition to these differences in understanding of plagiarism, there is evidence that students from different cultures (Hayes and Introna, 2005) and disciplines (Iyer and Eastman, 2006) do not define plagiarism in the same way, nor agree on its seriousness. Students from more collectivist cultures, such as China and India, tend to have a different understanding of 
plagiarism from students in more individualist Western cultures. For example, Hayes and Introna (2005) found that Asian and Chinese students viewed plagiarism differently from and as less serious than UK students. One explanation for this is that students from these areas have been influenced by a very different educational system which places less emphasis on critical analysis than that expected in UK universities. Such students face the added difficulty of writing academically in a second language, a situation in which it would be reasonable for them to expect the original sources to express concepts much more clearly than they could themselves. Robinson and Kuin (1999) explored the possibility that different ethnic groups have varying perceptions of plagiarism. Their results, albeit from a small sample, suggest that Chinese students have a perception of what is acceptable in terms of working together that is different from the Western view and which may derive from their collectivist culture which places a high value on cooperation and group work .

Other studies however, find that culture has no effect on students' perceptions of plagiarism (Yeo, 2007). Schmitt (2005, p69) comments that:

"Although cultural reasons are given to explain why some students from some countries appear to 'borrow text' more than others, most students I have met understand the concept of plagiarism regardless of where they come from. They may not, however, understand the specifics of what is considered to constitute plagiarism or may consider it a valid writing strategy."

This comment alerts us to the interesting proposition that it may not be differing perceptions of plagiarism which are at issue, but a conscious decision to use plagiarism as a writing strategy. Carroll and Ryan (2005) use the analogy of international students being "canaries in the coalmine" to highlight the challenges of guiding all students through the adjustment to academic writing norms and potential plagiarism issues regardless of their cultural background. 
Some studies have found that students from different disciplines view academic dishonesty differently and are more or less likely to engage in acts which are considered to be plagiarism by the academic community. One study reported science and technology students as most likely to cheat (Newstead et al., 1996) while another (Caruana et al., 2000) claimed that business students are the most unethical. These studies were not limited to plagiarism: much of the literature does not separate out plagiarism from other forms of academic misconduct or conflates explorations of perceptions with prevalence. In a study of the prevalence of cheating in written tests and assignments Premeaux (2005) suggests that business students live in a society which blurs the lines between right and wrong, and possibly even expects unethical behaviour from its leaders. Premaux notes that it is a particular concern that some lecturers and teachers now think that students do not see cheating as wrong.

\section{Plagiarism Research}

Studies which investigate perceptions of plagiarism often do more than simply ask for a definition. Many studies investigate the prevalence of student academic misconduct in differing scenarios, others link prevalence of academic misconduct with perceptions of what constitutes academic misconduct. For example Bisping et al (2008) record student responses to 31 forms of academic misconduct offering the responses of "have done it knowing it was wrong" and "have done it". The results of the study were interpreted using econometrics modelling to explore possible correlations between likelihood and perceptions of seriousness and also between likelihood and other variables recorded, for example GPA.

Another approach is to use scenarios to investigate perceptions of plagiarism and to ask respondents to decide whether the action described is plagiarism and how serious the misconduct is. The seriousness with which different forms of academic misconduct are viewed often depends on whether the act occurs in-class, like an exam, or out of class, like 
coursework, and how active or passive the act was (Levy and Rakovski, 2006). Interestingly, the passive, out-of-class acts were also the ones where there was most disagreement about definition and seriousness. Many acts of plagiarism fall into this category, such as allowing someone to copy work for an assignment, meaning that plagiarism is generally viewed as less serious than say, cheating in an exam. Institutional policies, however, often label plagiarism as just as serious as exam cheating and impose the same penalties.

If institutions are to deal with plagiarism fairly and consistently, a clear picture of students' perceptions of plagiarism needs to be developed. Where student understanding does not fit with the institutional definition, guidance should be provided to properly educate the students, rather than assuming they will "pick up" the information they need and interpret it correctly. This will ensure that students are treated fairly, and will also help to assuage the worry that they might plagiarise without knowing it.

The study reported here arose in response to concerns arising from cases of plagiarism (particularly the demographic profile of students charged with plagiarism) and numerous studies and anecdotal evidence that plagiarism and misconduct in university assessments is on the increase across the HE sector. Associated with this issue was the concern that students may not be given appropriate specific guidance on how to avoid plagiarism. This latter concern includes consideration of the approach to study of students from different cultural groups or those who have previous educational experience in regions other than Europe. There are a substantial number of international students studying in the UK; addressing the needs of these students in adjusting to the conventions of study and to the expectations of academic work in the UK is important in order to ensure they are not disadvantaged, particularly where English is their second language.

Much of the research on plagiarism uses qualitative approaches, which are useful in explaining the different meanings that individuals or groups assign to the concept. However, 
these studies frequently have a restricted sample in terms of demographics or size. The current study has employed a large scale survey, providing statically robust data that can be utilised to test the findings from previous research. It explicitly separates perceptions of the seriousness of the misconduct scenarios described from any question of whether students themselves had engaged in plagiarism or other forms of academic misconduct. This was emphasised in the briefing given to students before the questionnaire was distributed. This approach should minimise any biasing of responses through linking perceptions of academic misconduct with actions to which students attach a moral judgement.

\section{Method}

\section{Measures}

A short questionnaire was distributed to undergraduate and postgraduate students attending Business Schools at three different universities, one Australian and two UK (one pre-1992 and one post-1992 institution). At the pre-1992 UK university, students in the Arts and Biological Sciences faculties were also surveyed as part of a university-wide investigation of how to best support the development of students' academic skills. Participation was voluntary and questionnaires were distributed during lecture time.

Demographic information was collected, including the students' region of origin, region of education prior to the current course, and current year of study. The questionnaire is presented in Appendix 1. Part I of the questionnaire, the results of which are reported here, consisted of 20 scenarios briefly describing possible plagiarism or academic malpractice, which respondents were asked to rate in terms of their "seriousness" on a 5-point scale: $1=$ not plagiarism, $2=$ not serious, $3=$ minor offence, $4=$ serious and $5=$ very serious. Examples of items are:

- Item 1: Copying sentences and making small changes such as replacing or changing the order of the words, without referencing the source. 
Item 7: Proposing an idea or view without knowing this has been proposed by others and so not listing relevant articles in the reference list.

Part II of the questionnaire collected information on what sources students had found most helpful in developing their understanding of plagiarism and is not reported here.

\section{Participants}

Over 2,500 responses were collected. Table 1 shows the number of responses by University, Faculty and Year.

---Table 1 about here---

Sixty-three percent of respondents were previously educated in Europe, $16 \%$ in China and South-East Asia, and 15\% in Australia. The remaining 6\% were spread over other regions and excluded from comparative analyses.

\section{Results}

To explore the underlying structure of student perceptions of plagiarism, the data was factor analysed. Factor analysis allows the identification of similarities in how respondents view the different items. PCA (Principal component analysis) extracted four factors with eigenvalues over 1 , accounting for $51 \%$ of the variance (Table 2 ). The majority of items loaded clearly on a single factor, with the exception of the item "Resubmit own work", which was therefore excluded from further analysis which used this factor structure. A few items had secondary loadings and are indicated in the table. Examination of the scree plot (Figure 1) indicated a three factor solution was more appropriate than four, however. The fourth factor, with an eigenvalue of 1.03 , accounted for only $5 \%$ of the variance and included "control" items which were examples of good referencing practices and was therefore excluded from further analysis. 
--- Figure 1 about here ---

--- Table 2 about here ---

Inspection of the item loadings helps to interpret these factors and reveal the themes in students' understandings of plagiarism. Factor 1 had an eigenvalue of 4.97 and accounted for $25 \%$ of the variance. Items which load highly on the first factor could be described as acts which constitute active "cheating" on an assignment, including stealing or buying an assignment and submitting it as one's own, leading to an interpretation of this scale as a dishonest subscale.

Factor 2 had an eigenvalue of 2.84 , accounting for $14 \%$ of the variance. This factor included items which involved sharing information with colleagues, indicating perhaps that students are unsure of whether these acts are "group work" or "plagiarism". High-loading items were acts such as passing on assignments or outlines to friends and using text from a study group. In addition, items which represent poor scholarship but which do not actually harm another person, such as including references the student has not actually read or unwittingly duplicating an idea, also loaded reasonably well on this factor. Overall this factor represents acts which are poor scholarship but are perhaps not viewed as active plagiarism in the same way as the first factor.

Factor 3 had an eigenvalue of 1.3 and accounted for $7 \%$ of the variance. Items loading most clearly on this factor included those representing poor referencing techniques, such as referencing at the end of a piece of work only. Four of the 6 items in this factor loaded somewhat on other factors as well, indicating that these items were split between those viewed as dishonest (factor 1) and not plagiarism (factor 4) 
In summary then, the first factor deals with dishonest acts, the second factor mainly with the issue of group work and the third factor with poor referencing. These three factors were examined for their reliability as subscales. Cronbach suggests that alphas above 0.7 indicate a reliable scale. Analysis indicated that the Dishonest scale had good reliability $(\alpha=0.85)$ while the Group Work scale was reasonably reliable (0.69). The Poor Referencing scale, however, had a relatively low alpha (0.57) and care should therefore be taken with interpretation.

Rather than analysing each individual item on the questionnaire, subsequent analyses combined items according to these factors and used them as subscales to explore student perceptions and Table 3 presents the descriptive statistics for these subscales.

--- Table 3 about here ---

\section{Comparisons of student perceptions}

Stage of Study

Independent samples t-tests were conducted to compare undergraduate (UG) and postgraduate (PG) perceptions across all universities. There were no differences between UG and PG perceptions on the Dishonest $\left(\mathrm{t}_{2647}=-0.78, \mathrm{p}>0.05\right)$ or Group Work $\left(\mathrm{t}_{460}=-1.24\right.$, $p>0.05$ ) scales. Students did differ, however, in their perceptions of the seriousness of Poor Referencing $\left(\mathrm{t}_{459}=-2.89, \mathrm{p}<0.01\right)$, with PG students (mean 3.5) believing these acts were slightly more serious than UG students (mean 3.4) believed they were. This difference, despite being significant, represents a very small variation in opinion with both groups of students perceiving these acts as minor offences.

One way ANOVA was conducted on the UG students only and found no significant differences between students in different years of their undergraduate degree. 


\section{Faculties}

Perceptions of students in different faculties at the same institution, UK1, were compared using one way ANOVA with post-hoc Bonferroni tests. Table 4 shows the descriptive statistics for each faculty.

--- Table 4 about here ---

There were significant differences on all three themes: Dishonest $\left(F_{2,1835}=27.9\right.$, $\mathrm{p}<0.01$, partial $\left.\eta^{2}=0.03\right)$, Group Work $\left(\mathrm{F}_{2,1840}=5.96, \mathrm{p}<0.01\right.$, partial $\left.\eta^{2}=0.006\right)$ and Poor Referencing $\left(F_{2,1845}=22.15, \mathrm{p}<0.01\right.$, partial $\left.\eta^{2}=0.022\right)$. Although significant, these differences represent small effect sizes. Post-hoc tests showed significant differences between all three faculties on the Dishonest subscale: at the $\mathrm{p}<0.001$ level for the Business School and both Biological Sciences and Arts, and at the $\mathrm{p}<0.01$ level between Biological Sciences and Arts. For the Group Work subscale, the Arts Faculty had a significantly lower mean than both the Business School and Biological Sciences $(\mathrm{p}<0.01)$. The Poor Referencing subscale showed significant differences at the $\mathrm{p}<0.01$ level between the Business School and both Arts and Biological Sciences, while the difference between Arts and Biological Sciences was significant at the $\mathrm{p}<0.05$ level.

\section{Different universities}

Because the faculty could have an influence on students' perceptions, the effect of studying at different universities was explored using MANOVA within the Business School subsamples only. A significant difference was found for the Group Work subscale only $\left(F_{2,1682}=7.72, p<0.001\right.$, partial $\left.\eta^{2}=0.009\right)$. Post-hoc tests indicated this was due to a difference between the first UK university and the Australian university, with the UK students perceiving actions around group work as less serious. 


\section{Region of previous education}

Again keeping the faculty of study constant, the effect of students' previous educational region on their understandings of plagiarism was explored using MANOVA within the Business School subsamples only.

---Table 5 about here ---

A significant main effect of region of previous education was found, though with only a small effect size $\left(\mathrm{F}_{6,2664}=18, \mathrm{p}<0.001\right.$, partial $\left.\eta^{2}=0.04\right)$. Analysis of each subscale indicated that the significant difference held true for all three, though effect size was still small: Dishonest $\left(\mathrm{F}_{2,1333}=4.78, \mathrm{p}<0.01\right.$, partial $\left.\eta^{2}=0.007\right)$, Group Work $\left(\mathrm{F}_{2,1333}=23.02\right.$, $p<0.001$, partial $\left.\eta^{2}=0.033\right)$ and Poor Referencing $\left(F_{2,1333}=10.8, p<0.001\right.$, partial $\left.\eta^{2}=0.016\right)$. Post-hoc Bonferroni tests indicated that students who had previously been educated in Europe and Australia differed in their understandings of the Group Work subscale only $(\mathrm{p}<0.05)$, while students previously educated in China/SE Asia significantly differed from the other two regions on all three subscales, feeling that Dishonest and Poor Referencing acts were less serious and Group Work behaviours more serious than European or Australian students.

\section{Discussion}

Rather than analyse individual item responses, this study has developed a model for understanding how students view plagiarism. It identified three factors or subscales: Dishonest behaviours were viewed as most serious, followed by actions representing Poor Referencing, and with Group Work behaviours as least serious. These findings relate well to previous work in the area and may provide a succinct, robust model to integrate findings from across the world. Brimble and Stevenson Clarke (2005) investigated academic dishonesty in Australian Universities, looking at both perceptions of seriousness and prevalence. Responses 
indicated that students did not regard sharing information on individual assignments as being serious, the majority of them having engaged in this practice and indicating that it should attract no penalty. Similar findings were reported by Rakovsky and Levi (2007) in a study of American Business Schools, where working collaboratively on individual assignments was something most of the students had engaged in and also considered least serious. Bisping et al (2008) found that while the majority of students had worked with others on an individual assignment, only a small minority had done this knowing it was wrong. In contrast, both Brimble and Stevenson Clarke (2005) and Bisping et al (2008) found only a small minority of students had copied others' assignments, and this behaviour was viewed as more clearly "wrong". These findings are consistent with those reported here that the Dishonest factor is considered most serious while practices resulting from collaborative working are considered least serious.

Qualitative work by Ashworth et al (1997) showed that there is a clear moral basis to students' views on plagiarism, with acts reflecting friendship and good learning considered good or at least justifiable even if they attracted penalties. This research shows similar results in the factor analysis. The first factor consisted of items that students rated as very serious and indicated that students were making moral decisions based on more than simple plagiarism rules. The seriousness of an act was determined not only by whether it was considered plagiarism or not, but by its relative anti-social character rating as well. Thus, items involving stealing from someone or coercion loaded high on this factor. The second factor involved items which, while often considered plagiarism in university policies, involved working with peers or were considered not harm others. Ashworth et al's (1997) work also sheds light on why these items may have loaded together on one factor. It is possible that students are well aware that these acts are considered academic misconduct, but perhaps they make a judgement that these should be treated less seriously than acts which are considered morally 
suspect. Items which were clearly understood as plagiarism and did not involve others loaded on the third factor. This again is a good indication that there is more to students' understanding of plagiarism than a simple list of rules of what constitutes plagiarism, as these acts did not involve the moral dimension or group work.

\section{Comparisons between groups}

Several sub-groups of the sample were compared to find out how students from different backgrounds understood plagiarism. Flint et al (2006) found in a qualitative research project that staff had varying understandings of plagiarism, and that certain models of understanding were restricted to certain disciplines. This study demonstrates that differences in student understanding dependent on faculty is also clearly evident.

Some authors have suggested that Business students are less ethical than students in other faculties when it comes to cheating or plagiarising at university (Caruana et al., 2000), although this has been challenged by research which failed to find a difference (Iyer and Eastman, 2006). The findings of the present study are consistent with the hypothesis that Business students view plagiarism as less serious than students from other faculties. However, again it should be noted that these differences were small and do not likely represent greatly differing perceptions in student views.

Only one difference was found between students studying at different universities, which implies that there is a greater similarity in the perceptions of plagiarism by students in the same discipline than by students at the same university.

This study also found that postgraduate students in the UK tended to view poor referencing as more serious than undergraduate students. It could be postulated that postgraduate students are more invested in the academic culture and therefore view referencing as more important than students who have been less exposed to the academic environment. 
There is a commonly held belief that culture is the main determinant of a students' perceptions of plagiarism, with research showing that students from different cultures view plagiarism in different ways (Hayes and Introna, 2005). The results of this study are consistent with previous findings, with significant differences found between students who had previously been educated in China/SE Asia and students from Australian or British education systems. Interestingly, however, these findings were somewhat contrary to what might be expected in the literature, with students from the more collectivist cultures viewing actions related to group work as more suspect than students from more individualistic cultures. While a full explanation awaits further study, this may perhaps indicate a "contrast" effect, where students focus on the information they have received that seems most in contrast with their previous background. Thus, students from collectivist cultures may be surprised about rules against group work and remember most clearly that collusion is frowned on, while students from more individualist cultures may focus on how they are "allowed" to collaborate to a certain extent.

A key finding of the study is that the length of time a student has been exposed to university life (their level of study) does not seem as important a factor in their perceptions of plagiarism as where they have previously been educated and the discipline they are currently studying.

\section{Limitations of the study}

Although this study used a very large international sample and was able to develop a reasonably robust model for understanding student perceptions of plagiarism, it should be noted that all of the differences between groups found here had small to very small effect sizes. The large sample means that even small variations in opinion are identified as statistically significant even when not representing substantive divergence in opinion. Secondly, although differences were found between students from different educational 
regions, these regions were very broad. Future research into the effect of culture and previous education could use more specific measures of relevant cultural issues such as collectivism in order to refine results.

\section{Conclusion}

This study has developed a model for understanding how students perceive plagiarism, demonstrating three main factors that underlie perceptions of the seriousness of different behaviours. This model integrates well with previous findings, provides a promising paradigm for future research and a basis for educational interventions. For example, these findings demonstrate that lecturers setting group work tasks need to clearly establish the boundaries of collaborative effort and also indicate when it is appropriate to complete assessment tasks within a group. Effective strategies to make these somewhat blurred boundaries are clearly needed. The model has also shown that students vary somewhat in their perception of plagiarism, depending on their faculty, university, and region of previous education. However, the use of a large and broad sample has also indicated that these differences are relatively small and that there may be a widespread, general consensus amongst students as to what plagiarism is and the seriousness of different acts. A striking finding of this study, universally expressed by all groups of respondents, is that behaviours involved in working together on individual assignments are not considered very serious. Where that perception differs from institutional policy or staff perceptions explicit guidance and more training needs to be given to ensure that students have a clear understanding of what is expected of them. 


\section{References}

ASHWORTH, P., BANNISTER, P. \& THORNE, P. 1997. Guilty in whose eyes? University students' perceptions of cheating and plagiarism in academic work and assessment. Studies in Higher Education, 22, 187-203.

BARRETT, R. \& COX, A. L. 2005. 'At least they're learning something': the hazy line between collaboration and collusion. Assessment and Evaluation in Higher Education, $30,107-122$.

BISPING, T. O., PATRON, H. \& ROSKELLEY, K. 2008. Modeling Academic Dishonesty: The Role of Student Perceptions and Misconduct Type. Journal of Economic Education, Winter, 4-21.

BRIMBLE, M. \& STEVENSON-CLARKE, P. 2005. Perceptions of the Prevalence and Seriousness of Academic Dishonesty in Australian Universities. The Australian Educational Researcher, 32, 19-44.

CARROLL, J. 2007. A Handbook for Deterring Plagiarism in Higher Education, Oxford, Oxford Centre for Staff Learning and Development.

CARROLL, J. \& RYAN, J. 2005. Teaching International Students: Improving Learning for All, London, Routledge.

CARUANA, A., RAMASESHAN, B. \& EWING, M. T. 2000. The effect of anomie on academic dishonesty among university students. The International Journal of Educational Management, 14, 23-29.

FLINT, A., CLEGG, S. \& MACDONALD, R. 2006. Exploring staff perceptions of student plagiarism. Journal of Further and Higher Education, 30, 145-156.

HAYES, N. \& INTRONA, L. D. 2005. Cultural Values, Plagiarism, and Fairness: When Plagiarism Gets in the Way of Learning. Ethics and Behavior, 15, 213-231. 
IYER, R. \& EASTMAN, J. K. 2006. Academic Dishonesty: Are Business Students Different From Other College Students? Journal of Education for Business, November/December.

LEVY, E. S. \& RAKOVSKI, C. C. 2006. Academic Dishonesty: A Zero Tolerance professor and Student Registration Choices. Research in Higher Education, 47, 735-754.

LIVOSKY, M. \& TAUBER, R. T. 1994. Views of Cheating Among College Students and Faculty. Psychology in the Schools, 31, 72-81.

NEWSTEAD, S., FRANKLYN-STOKES, A. \& ARMSTEAD, P. 1996. Individual differences in student cheating. Journal of Educational Psychology, 88, 229-241.

PARK, C. 2003. In Other (People's) Words: plagiarism by university students - literature and lessons. Assessment and Evaluation in Higher Education, 28, 471-488.

PREMEAUX, S. R. 2005. Undergraduate Student Perceptins Regarding Cheating: Tier 1 Versus Tier 2 AACSB Accredited Business Schools. Journal of Business Ethics, 62, 407-418.

RAKOVSKI, C. C. \& LEVY, E. S. 2007. Academic Dishonesty: Perceptions of Business Students. College Student Journal, 41, 466-481.

ROBINSON, V. \& KUIN, L. 1999. The explanation of practice: why Chinese students copy assignments. International Journal of Qualitative Studies in Education, 12, 130-210.

SCHMITT, D. 2005. Writing in the International Classroom. In: CARROLL, J. \& RYAN, J. (eds.) Teaching International Students: Improving Learning for All. London: Routledge.

SMITH, D. 26 Feb 2006. Da Vinci trial pits history against art. Observer, p.14.

TENNANT, P. \& DUGGAN, F. 2008. Academic Misconduct Benchmarking Research Project II:The Reported Incidence of Student Plagiarism and the Penalties Applied [Online]. HE Academy. Available: 
http://www.heacademy.ac.uk/assets/York/documents/AMBeR_PartII_Full_Report.pdf 2008].

YEO, S. 2007. First-year university science and engineering students' understanding of plagiarism. Higher Education Research \& Development, 26, 199-216. 
Table 1: Number of respondents

\begin{tabular}{|c|c|c|c|c|c|c|c|}
\hline University & Faculty & 1st year & 2nd year & $\begin{array}{l}\text { Year } \\
\text { 3rd year }\end{array}$ & Masters & MBA & TOTAL \\
\hline \multirow[t]{3}{*}{ UK 1} & Business & 232 & 228 & 178 & 206 & 39 & 883 \\
\hline & $\begin{array}{l}\text { Biological } \\
\text { Sciences }\end{array}$ & 282 & 141 & 33 & 37 & 0 & 493 \\
\hline & Arts & 360 & 95 & 24 & 0 & 0 & 479 \\
\hline UK 2 & Business & 159 & 0 & 0 & 26 & 32 & 217 \\
\hline \multirow[t]{2}{*}{ Australia } & Business & 581 & 18 & 0 & 0 & 0 & 599 \\
\hline & TOTAL & 1614 & 482 & 235 & 269 & 71 & 2671 \\
\hline
\end{tabular}


Table 2: Descriptive statistics and rotated factor loadings for questionnaire items

\begin{tabular}{|c|c|c|c|c|c|c|}
\hline & \multirow[b]{2}{*}{ Mean } & \multirow[b]{2}{*}{ SD } & \multicolumn{4}{|c|}{ Rotated factor loading } \\
\hline & & & 1 & 2 & 3 & 4 \\
\hline Stealing Assignment & 4.81 & .634 & .807 & -.085 & .139 & -.101 \\
\hline Buying Assignment & 4.72 & .733 & .801 & .000 & .110 & -.042 \\
\hline Coercing Other & 4.67 & .812 & .766 & .006 & -.018 & -.054 \\
\hline Friend Writes & 4.45 & .904 & .756 & .108 & .117 & -.014 \\
\hline Stealing Text & 4.25 & .874 & .662 & .268 & .119 & .009 \\
\hline Download Plus Own Intro & 4.44 & .854 & .558 & .044 & .464 & -.126 \\
\hline Copying Thesis & 4.54 & .944 & .543 & -.015 & .280 & -.104 \\
\hline Passing On Outline & 2.20 & 1.169 & .003 & .755 & -.024 & .116 \\
\hline Study Group Using Text & 3.14 & 1.119 & .183 & .634 & .241 & -.083 \\
\hline $\begin{array}{l}\text { Study Group Not Using } \\
\text { Text }\end{array}$ & 1.79 & 1.113 & -.076 & .622 & -.113 & .259 \\
\hline Passing On Assignment & 3.45 & 1.148 & .382 & .596 & -.009 & .043 \\
\hline Unread References & 2.64 & 1.066 & .045 & .506 & .243 & .061 \\
\hline $\begin{array}{l}\text { Unwitting Idea } \\
\text { Duplication }\end{array}$ & 1.69 & .978 & -.183 & .446 & .155 & .360 \\
\hline $\begin{array}{l}\text { Unreferenced Small } \\
\text { Changes }\end{array}$ & 3.40 & 1.055 & .128 & .036 & .734 & .116 \\
\hline Unreferenced Quote & 4.34 & .934 & .364 & -.003 & .625 & -.149 \\
\hline Referenced At End Only & 1.96 & 1.029 & -.041 & .205 & .535 & .360 \\
\hline Combine With Friend & 3.89 & 1.046 & .379 & .270 & .426 & -.113 \\
\hline Referenced Quote & 1.29 & .764 & -.096 & .138 & -.054 & .779 \\
\hline Changed Quote With Ref & 1.64 & 1.008 & -.023 & .101 & .104 & .764 \\
\hline Resubmit Own Work & 4.04 & 1.173 & .269 & .113 & .247 & .142 \\
\hline
\end{tabular}

Highest factor loading is indicated in bold.

Secondary loadings over 0.3 are indicated in italics. 
Table 3: Descriptive Statistics and Reliability Analysis of the factors

\begin{tabular}{lrrr}
\hline Factor & Mean & SD & $\mathbf{\alpha}$ \\
\hline Dishonest & 4.55 & .60 & .85 \\
Group Work & 2.48 & .69 & .69 \\
Poor referencing & 3.39 & .68 & .57 \\
\hline
\end{tabular}


Table 4: Descriptive statistics by Faculty

\begin{tabular}{llcrc} 
& & N & Mean & SD \\
\hline Dishonest & Business & 874 & 4.48 & .64 \\
& Biological Sciences & 486 & 4.61 & .60 \\
Group Work & Arts & 478 & 4.72 & .42 \\
& Business & 875 & 2.46 & .71 \\
& Biological Sciences & 487 & 2.50 & .67 \\
Poor Referencing & 478 & 2.35 & .62 \\
& Arts & 878 & 3.33 & .70 \\
& Business & 492 & 3.46 & .65 \\
& Biological Sciences & 478 & 3.58 & .62 \\
\hline & Arts & & &
\end{tabular}


Table 5: Descriptive statistics for previous region of education (Business students only)

\begin{tabular}{llrrr} 
& Previous Education & Mean & SD & $\mathrm{N}$ \\
\hline Dishonest & Europe & 4.53 & .56 & 661 \\
& China and SE Asia & 4.41 & .76 & 339 \\
& Australia & 4.54 & .61 & 336 \\
Group Work & Europe & 2.39 & .68 & 661 \\
& China and SE Asia & 2.70 & .75 & 339 \\
& Australia & 2.51 & .68 & 336 \\
Poor & Europe & 3.39 & .65 & 661 \\
Referencing & China and SE Asia & 3.18 & .73 & 339 \\
& Australia & 3.32 & .67 & 336 \\
\hline
\end{tabular}


Figure 1: Scree Plot

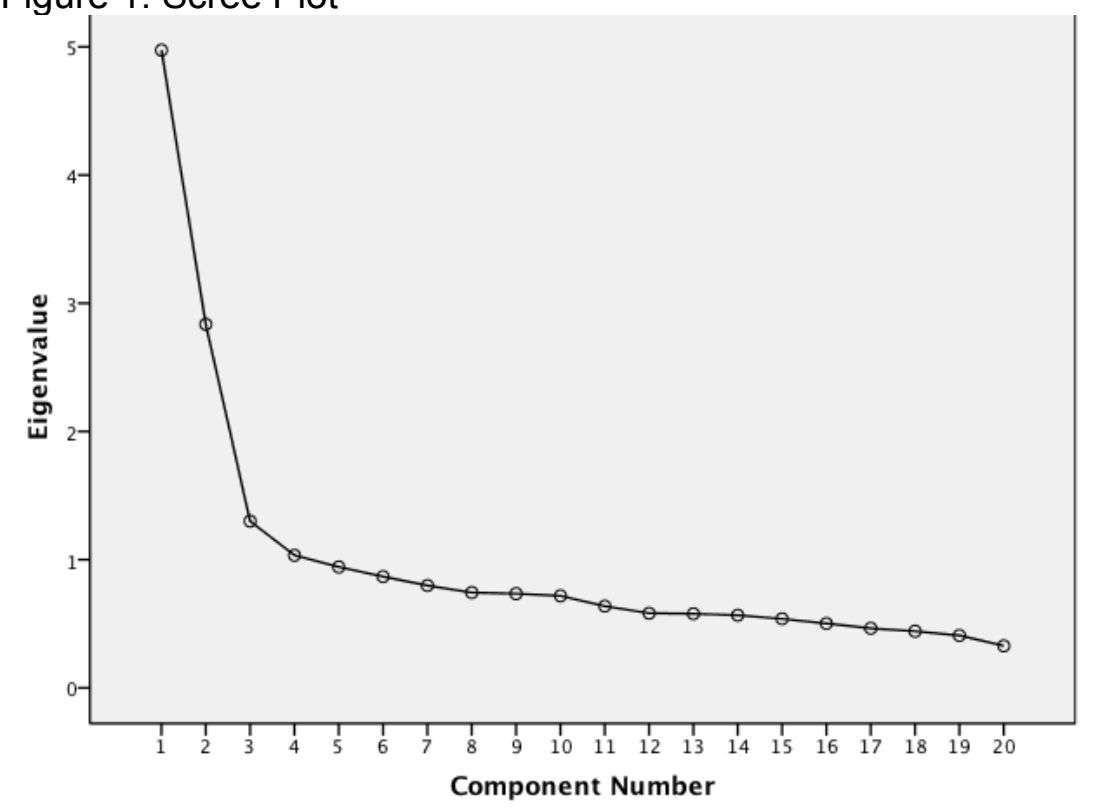

